\title{
Scavenging activity of Magnéli phases as a function of $\mathrm{Ti}^{4+} / \mathrm{TH}^{3+}$ ratios
}

\section{Canillas, ${ }^{* a}$ E. Chinarro,a A. P. Pêgobc and B. Morenoa}

\author{
* Corresponding authors \\ a Ceramic and Glass Institute (ICV), Spanish National Research Council (CSIC), C/ Kelsen 5, Campus de \\ Cantoblanco, Madrid, Spain \\ E-mail: mcanillas@icv.csic.es \\ b INEB - Instituto de Engenharia Biomédica and i3S - Instituto de Investigação e Inovação em Saúde, \\ Universidade do Porto (UPorto), Rua Alfredo Allen, 208, 4200-135 Porto, Portugal \\ c ICBAS - Instituto de Ciências Biomédicas Abel Salazar, UPorto, Portugal \\ † Electronic supplementary information (ESI) available. See DOI: 10.1039/c7cco5862d
}

Originally published in Chem. Commun., 2017, 53, 10580. DOl:10.1039/c7cco5862d

\begin{abstract}
$\mathrm{TiO}_{2}$ is able to scavenge reactive oxygen and nitrogen species (ROS and RNS) in the absence of light. The scavenging mechanism has been related to the chemistry of defects (oxygen vacancy reduced oxidation states of Ti) but it is still unknown. This study describes the ROS scavenging activity of different titanium oxide phases and relates their scavenging activities with the $\mathrm{Ti}^{4+} / \mathrm{Ti}^{3}$ molar ratio as well as the band gap value. The $\mathrm{Ti}_{5} \mathrm{O}_{9}$ phase, with a mixture of both oxidation states, presented a substantially higher percentage of 2,2-diphenyl-1-picrylhydracyl radicals ( $\mathrm{DPPH}^{*}$ ) eliminated per $\mathrm{m}^{2}$ of specific surface area in comparison to phases with predominant oxidation states $\mathrm{Ti}^{+}{ }^{+}$or $\mathrm{Ti}^{+}$such as $\mathrm{TiO}_{2}$ and $\mathrm{Ti}_{2} \mathrm{O}_{3}$, respectively. The obtained results indicate that the DPPH scavenging mechanism corresponds to a catalytic process on the $\mathrm{Ti}_{5} \mathrm{O}_{9}$ surface which is facilitated by the presence of charges that can easily move through the material. The mobility of charges and electrons in the semiconductor surface, related to the presence of oxidation states $\mathrm{Ti}^{4+}$ and $\mathrm{Ti}^{3+}$ and a small band gap, could create an attractive surface for radical species such as DPPH . This puts forward $\mathrm{Ti}_{5} \mathrm{O}_{9}$ as a promising candidate coating for implantable biomedical devices, as an electrode, since it can cushion inflammatory processes which could lead to device encapsulation and, consequently, failure.
\end{abstract}


Previous studies have demonstrated that $\mathrm{TiO}_{2}$ neutralizes the reactive oxygen and nitrogen species

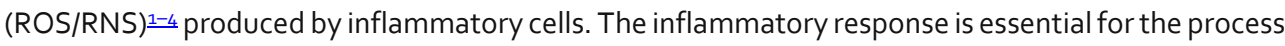
of tissue repair to occur but when exacerbated it can lead to the encapsulation of the implant. For this reason, a material able to reduce the amount of ROS created in the surroundings of the implant can reduce significantly its rejection.. .5

The scavenging mechanism carried out by $\mathrm{TiO}_{2}$ to neutralize radical species has not been completely unravelled. In the first step, titanium-peroxide gel interaction was studied through the Fenton

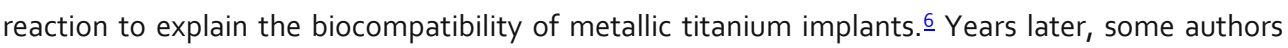
suggested that it proceeds through the following redox reactions. ${ }^{3}$

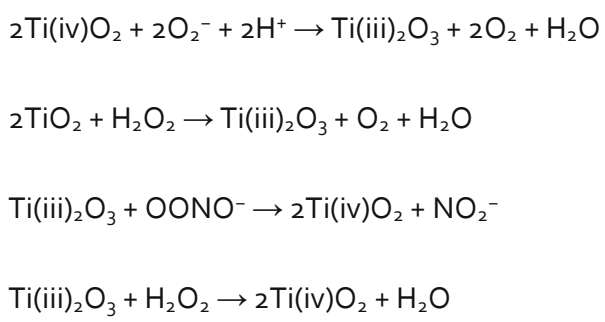

However, a mechanism based on redox reactions, which involved crystal phase changes, would require harsh redox conditions that hardly can exist in the physiological environment.

The scavenging process seems to be complex and different parameters could be involved. In fact, the scavenging activity has been related with the chemistry of defects. $\frac{2-10}{-10}$ These authors concluded that the antioxidant activity was in direct relation to the $\mathrm{Ti}^{3+}$ concentration in the sample.4.11 Substoichiometric structures of $\mathrm{TiO}_{2}$, well-known as Magneli phases, can be obtained from $\mathrm{TiO}_{2}$ via thermal treatment in a reducing atmosphere.12 They are characterized by ordered oxygen vacancies, which are compensated by $\mathrm{Ti}^{3+}$. On this basis, they should be biocompatible materials that are able to neutralize ROS.

From all the titanium Magneli phases, $\mathrm{Ti}_{5} \mathrm{O}_{9}$ and $\mathrm{Ti}_{4} \mathrm{O}_{7}$ have been widely investigated as electrodes $\underline{13-}$ 15 due to their excellent electrochemistry $\underline{16-19}$ and high corrosion resistance under very aggressive conditions. $\underline{12,20} \mathrm{Ti}_{5} \mathrm{O}_{9}$ has been also proposed as an electrode for biomedical applications. $\underline{21}$ When considering implantable electrodes, the prevention of fibrous capsule formation around the electrode, as a result of an inflammatory process, is of major importance since it can compromise the electrode function.

In this work, the radical scavenging activity of the Magneli series-type oxide $\mathrm{Ti}_{5} \mathrm{O}_{9}$ is studied for the first time, and compared with those of other commercial materials with different $\mathrm{Ti}^{+} / \mathrm{Ti}^{+}+$ratios. The differences between the scavenging activities of different reduced phases and $\mathrm{TiO}_{2}$ will be related to the presence of Ti in oxidation states III and IV in these phases and with the band gap measured for the samples.

$\mathrm{Ti}_{5} \mathrm{O}_{9}$ was obtained by thermal reduction of $\mathrm{TiO}_{2}$ powders. $\mathrm{TiO}_{2}$ was synthesized via a precipitation route, as described elsewhere. $\underline{22}$ Subsequently, $\mathrm{TiO}_{2}$ powders were calcined in air at $600{ }^{\circ} \mathrm{C} / 12 \mathrm{~h}$ to remove residuals from the synthesis. The reduction step was performed in a $\mathrm{N}_{2} / \mathrm{H}_{2}(90: 10)$ controlled atmosphere at $1400^{\circ} \mathrm{C}$ for 12 hours and the heating rate used was $5^{\circ} \mathrm{C} \mathrm{min}-1$. Moreover, commercial 
powders of titanium oxide phases were chosen with the following criteria to be used as controls: powders which possessed $\mathrm{Ti}$ in different oxidation states $\left(\mathrm{Ti}^{4^{+}}\right.$and $\mathrm{Ti}^{+}{ }^{+}$), and powders with different crystallographic phase compositions. With this aim, commercial $\mathrm{TiO}_{2}$ powders with predominant anatase phase content (Sigma-Aldrich, ref. T8141), named as $\mathrm{TiO}_{2}-\mathrm{A}$, and rutile phase content (Sigma-Aldrich, ref. 204757), named as $\mathrm{TiO}_{2}-\mathrm{R}$, were chosen because $\mathrm{Ti}$ is mainly in the $\mathrm{Ti}^{+}$form. Although both materials have the same chemical composition, they show different crystallographic structures and band gap values. Also, commercial powders of $\mathrm{Ti}_{2} \mathrm{O}_{3}$ (Sigma-Aldrich, ref. 481033) were used as a control, as in these $\mathrm{Ti}$ is found in the $\mathrm{Ti}^{3+}$ form.

Subsequently, all materials were characterized. Phase identification of the powders used in this study was made by means of X-ray diffraction analysis performed in a Siemens D-5000 diffractometer (Bruker AXS GmbH, Karlsruhe, Germany). The crystalline phase percentages, in the case of $\mathrm{TiO}_{2}$ commercial powders, were calculated from the X-ray diffraction (XRD) pattern following the method described by Zachariah et al. (2008). .33 Narrow-scan analysis was conducted within the $2 \vartheta$ range of $20-30^{\circ}$ as the main diffraction maxima of $\mathrm{TiO}_{2}-\mathrm{A}$ and $\mathrm{TiO}_{2}-\mathrm{R}$ are contained within this range. The calculated percentages are semi-quantitative.

Fig. 1 shows the phase composition of commercial powders selected in this study, where $\mathrm{TiO}_{2}-\mathrm{A}$ presents anatase as the major phase (Fig. 1a), while the percentage of the rutile phase is less than $1 \%$. However, $\mathrm{TiO}_{2}-\mathrm{R}$ possesses $94 \%$ rutile phase content and presents anatase as the minor phase (Fig. $\underline{1 b})$. In the case of reduced phases, $\mathrm{Ti}_{2} \mathrm{O}_{3}$ commercial powders are presented as the major phase with traces of anatase ( $\underline{\mathrm{Fig} . \mathrm{IC}}$ ) and $\mathrm{Ti}_{5} \mathrm{O}_{9}$ powders present a main phase of $\mathrm{Ti}_{5} \mathrm{O}_{9}$ and a secondary minor phase of $\mathrm{Ti}_{6} \mathrm{O}_{11}$ (Fig. 1d).

The band gap of the different titanium oxide powders was determined by measuring the absorbance in the ultraviolet-visible (UV-Vis) range of the powders using a spectrophotometer (UV-Vis-NIR Lambda 950, Perkin Elmer, USA). The measurements were carried out in the diffuse reflectance (DR) mode. The band gap was calculated using the equation according to Van Leeuwen et al. (Fig. 2) where the absorption coefficient $(\alpha)$ is related to the photon energy $(h \nu) . \underline{24}$

Table 1 resumes the physicochemical characterization of titanium oxide powders used in this study. Differences in the phase composition are translated into different band bap values, which decrease from $3.38 \mathrm{eV}$ for $\mathrm{TiO}_{2}-\mathrm{A}$ to $3.09 \mathrm{eV}$ corresponding to $\mathrm{TiO}_{2}-\mathrm{R}$. Regarding the reduced samples, the band gap values decrease to 1.62 and $1.02 \mathrm{eV}$ for $\mathrm{Ti}_{2} \mathrm{O}_{3}$ and $\mathrm{Ti}_{5} \mathrm{O}_{9}$, respectively (Fig. 2).

The 1,1-diphenyl-2-picryl-hydrazy radical (DPPH ', Sigma \#D9132) in 2-propanol (Sigma) was used to study the scavenging activity of the proposed samples. $\mathrm{DPPH}^{\circ}$ is a semi-stable radical which absorbs at $\lambda=517 \mathrm{~nm}$ (purple colour). In the presence of anti-oxidative agents in 2-propanol, the radical is neutralized as $\mathrm{DPPH}_{2}$. The absorption vanishes as the electron pairs off. The resulting decolourization is stoichiometric with respect to the number of electrons taken up. The DPPH concentration can be easily measured by UV-Vis absorbance aided by a calibration curve. Moreover, this semi-stable radical provides reasonable average lifetimes to work. This method has been widely used. $\underline{\underline{1-4}}$

The same amounts of five different titanium oxide samples were incubated in $0.1 \mathrm{mM}$ solution of $\mathrm{DPPH}^{\circ}$ in 2-propanol in the dark, to avoid scavenging by photocatalysis, for $30 \mathrm{~min}$. Then the suspension was centrifuged and the absorbance of the supernatant solutions was measured in a Power Wave XS (BIOTEC). 
Subsequently, the percentage of DPPH' eliminated was calculated from the ratio between the concentration corresponding to the maximum of absorbance (initial solution of DPPH') and concentrations corresponding to the absorbance of supernatant solutions. The materials studied possessed different specific surface areas, which increase the kinetics of the reaction. In order to evaluate the roles of $\mathrm{Ti}^{4}{ }^{+}$and/or $\mathrm{Ti}^{+}$or the band gap on the neutralization of $\mathrm{DPPH}^{*}$, the influence of the specific surface area of the powders was eliminated by plotting the percentage of DPPH eliminated calculated per $\mathrm{m}^{2}$ of specific surface area. The specific surface area was determined for all materials (Table 1) using the Brunauer-Emmett-Teller (B. E. T.) method in a Monosorb Analyzer MS13 (QuantaChrome Instruments, Boynton Beach, FL, USA). Then, the scavenging activities of different powders are compared according to \% of DPPH eliminated per mg of powder incubated and per $\mathrm{m}^{2}$ of specific surface area in each case. This is related to the oxidation state of $\mathrm{Ti}$ in each phase and the corresponding band gap.

Fig. 3 shows the percentages of DPPH ${ }^{*}$ eliminated per $\mathrm{mg}$ of powders and per $\mathrm{m}^{2}$ of specific surface area of different titanium oxide phases. These percentages are compared with the corresponding band gap values of each phase. The most remarkable result is that the highest percentage of DPPH eliminated per $\mathrm{m}^{2}$ is obtained by $\mathrm{Ti}_{5} \mathrm{O}_{9}$. This percentage value is almost sixty times higher than the percentage of $\mathrm{DPPH}^{\cdot}$ eliminated per $\mathrm{m}^{2}$ by $\mathrm{Ti}_{2} \mathrm{O}_{3}$, almost one hundred fifty times higher than the percentage for $\mathrm{TiO}_{2}-\mathrm{R}$ and more than two thousand times higher than the percentage corresponding to $\mathrm{TiO}_{2}-\mathrm{A}$. $\mathrm{Ti}_{5} \mathrm{O}_{9}$ is characterized by the smallest band gap value between the materials compared in the study. It should be noted that an important decrease in the band gap values, as it happens between $\mathrm{TiO}_{2}-\mathrm{R}(3.09 \mathrm{eV})$ and $\mathrm{Ti}_{2} \mathrm{O}_{3}(1.62 \mathrm{eV})$, does not mean an important increase in the percentage of $\mathrm{DPPH}^{\prime}$ eliminated. The percentage of $\mathrm{DPPH}^{*}$ eliminated by $\mathrm{Ti}_{5} \mathrm{O}_{9}$ is remarkably higher than the percentage eliminated by $\mathrm{Ti}_{2} \mathrm{O}_{3}$, but the difference between their band gap values is significantly smaller (band gap values $1.02 \mathrm{eV}$ and $1.62 \mathrm{eV}$, respectively).

It is known that the smaller the band gap, the higher the scavenging. However, this relationship is not directly proportional. This points to the fact that other parameters could be contributing to the noteworthy increase in the scavenging activity of $\mathrm{Ti}_{5} \mathrm{O}_{9}$. Additional important characteristics of $\mathrm{Ti}_{5} \mathrm{O}_{9}$ are the mixture of oxidation states and its conductivity. While $\mathrm{Ti}_{2} \mathrm{O}_{3}$ possesses $\mathrm{Ti}$ as $\mathrm{Ti}^{3+}$ and $\mathrm{TiO}_{2}$ possesses most of the $\mathrm{Ti}$ as $\mathrm{Ti}^{4+}, \mathrm{Ti}_{5} \mathrm{O}_{9}$ possesses $\mathrm{Ti}$ in both oxidation states, as $\mathrm{Ti}^{+}$and $\mathrm{Ti}^{+}$. Moreover, it exhibits a conductivity more than two orders of magnitude higher than $\mathrm{Ti}_{2} \mathrm{O}_{3}$ and $\mathrm{TiO}_{2}$. This probably implies that this mixture of valances allows a charge movement that benefits the reduction of radicals.

According to the hypothesis from other authors, the $\mathrm{DPPH}^{\cdot}$ reduction to $\mathrm{DPPH}_{2}$ should involve an oxidation of the scavenger materials. If the materials oxidise to reduce DPPH, it would imply that the reduced oxidation states of $(\mathrm{Ti}(\mathrm{iii}))$ should improve $\mathrm{DPPH}^{-}$elimination in comparison with the oxidised states ( $\mathrm{Ti}(\mathrm{iv})$ ). The decrease of the $\mathrm{O} / \mathrm{Ti}$ ratio means an increase in the amount of $\mathrm{Ti}^{+}$species and it would involve an improvement of the scavenger activity. According to this, the scavenging activity should increase in the following order: $\mathrm{TiO}_{2}\left(\mathrm{Ti}^{+}\right)<\mathrm{Ti}_{5} \mathrm{O}_{9}\left(\mathrm{Ti}^{+} / \mathrm{Ti}^{+}\right)<\mathrm{Ti}_{2} \mathrm{O}_{3}\left(\mathrm{Ti}^{3+}\right)$. In $\underline{\mathrm{Fig}_{3}} 3_{\mathrm{Ti}_{2}} \mathrm{O}_{3}$ increases the percentage of DPPH' eliminated per $\mathrm{m}^{2}$ compared to $\mathrm{TiO}_{2}$ phases, as was expected. However, $\mathrm{Ti}_{5} \mathrm{O}_{9}$, with a mixture of both oxidation states, further than demonstrating the highest scavenger activity shows an extraordinary increase with respect to $\mathrm{Ti}_{2} \mathrm{O}_{3}$. This could be explained if the scavenging mechanism does not involve changes in the material, such as phase changes, and the mechanism proceeds through a catalytic reaction which takes place on the surface of the material. To dismiss permanent phase changes, the XRD and band gap of $\mathrm{Ti}_{5} \mathrm{O}_{9}$ were studied before and after

INSTITUTO DE INVESTİGAÇÃO E INOVACCÃO EM SAÚDE UNIVERSIDADE DO PORTO

Rua Alfredo Allen, 208 4200-135 Porto Portugal +351220408800 
incubation in a DPPH solution under more aggressive conditions. Samples were incubated in $3 \mathrm{mM}$ $\mathrm{DPPH}^{\prime}$ solution for a longer period of time (the previously described scavenging assay was conducted in a DPPH solution of $0.1 \mathrm{mM}$, with an incubation period of $30 \mathrm{~min}$ ). After 15 days, DPPH is reduced to $\mathrm{DPPH}_{2}$ (Fig. 4) as indicated through the reduction of absorbance at $517 \mathrm{~nm}$. Under these conditions, important changes in the material should have been found as it would happen in a noncatalytic process. XRD analysis did not show changes of phases before and after the experiment (Fig. $\underline{1 d}$ and $\mathrm{e}$, respectively), which means that the mechanism does not involve a change of phase, which should be permanent after removing DPPH . Moreover, permanent changes in the structure or the oxidation state of Ti would affect the band gap, but differences found in the band gap values before and after incubation, $1.02 \mathrm{eV}$ before and $1.07 \mathrm{eV}$ after, are very small. Furthermore, an in situ assay has been realized. Thanks to its excellent electrochemical properties, $\mathrm{Ti}_{5} \mathrm{O}_{9}$ has been used as an electrode in a cyclic voltammetry DPPH' medium (Fig. $4 \mathrm{~B}$ ). No signals due to irreversible or reversible redox reactions have been recorded. The increases found in the intensity of the electric current and the double layer charge in the presence of $\mathrm{DPPH}^{*}$ confirm its interaction with the material surface.

Because of their semiconductor nature, these materials possess interesting catalytic and electric properties due to their special electronic configuration and electronic band structure. The mobility of the electrons, from the valence band to the conduction band, is responsible for these special properties and the band gap plays a key role. Also, it is well known the importance of the chemistry of defects in the special electrical properties of these semiconductors. For example, $\mathrm{Ti}_{5} \mathrm{O}_{9}$, which is an $\mathrm{n}$-type semiconductor with a small band gap value, possesses a mixture of $\mathrm{Ti}^{+} / \mathrm{Ti}^{4+}$ and shows a high conductivity at body temperature and a semiconductor-metallic transition at $55^{\circ} \mathrm{C} .15,21$ Electrons can be easily promoted to the conduction band where they possess a high mobility and the $\mathrm{Ti}^{3+} / \mathrm{Ti}^{4+}$ mixture increases the charge movement. This mobility could aid the chemisorption of radical molecules to the material surfaces improving the catalytic process. For these reasons, the scavenging activity has been related with both parameters $\mathrm{Ti}^{+} / \mathrm{Ti}^{+}$and the band gap.

Therefore, the mixture $\mathrm{Ti}^{+} / \mathrm{Ti}^{+}{ }^{+}$in $\mathrm{Ti}_{5} \mathrm{O}_{9}$, its band gap, its conductivity and the reduction of $\mathrm{DPPH}$ to $\mathrm{DPPH}_{2}$ without evidence of phase changes led us to suggest that the DPPH' scavenging mechanism corresponds to a catalytic process in the material surface. It is facilitated by the transport of charges that exists thanks to the presence of Ti(iii) and (iv) and their position in the structure of the material. Although the mechanism has not been elucidated yet, this study supports the excellent results obtained for $\mathrm{Ti}_{5} \mathrm{O}_{9}$ compared to $\mathrm{TiO}_{2}$ and $\mathrm{Ti}_{2} \mathrm{O}_{3}$.

Finally, the excellent scavenging activity of this material, in addition to the extraordinary properties as an electrode, strongly encourages its possible applications as an electrode in implantable medical devices. 


\section{Acknowledgements}

The authors would like to thank the Fundación General CSIC and Obra Social "La Caixa" (Project BIOAMD) for providing financial support to this work. Dr Canillas acknowledges the financial support received from the CSIC for her PhD JAEpre grant and Dr Moreno is grateful to the Fondo Social Europeo and CSIC for her JAEDoc contract.

\section{Conflicts of interest}

There are no conflicts to declare.

\section{REFERENCES}

1 R. Suzuki and J. A. Frangos, Clin. Orthop. Relat. Res., 1999, 362, 280.

2 R. Suzuki, J. Muyco, J. McKittrick and J. A. Frangos, J. Biomed. Mater. Res., Part A, 2003, 66(2), 396.

3 H. Sahlin, R. Contreras, D. F. Gaskill, L. M. Bjursten and J. A. Frangos, J. Biomed. Mater. Res., Part A, 2005, 77(1), 43 .

4 R. Contreras, H. Sahlin and J. A. Frangos, J. Biomed. Mater. Res., Part A, 2006, 80(2), 480.

5 R. D. Jayant, M. J. McShane and R. Srivastava, Int. J. Pharm., 2011, 403(1-2), 268.

6P. Tengvall, I. Lundstro“m, L. Sjo“ qvist and H. Elwing, Biomaterials, 1989, 10(2), 118.

7 I. N. Martianov, T. Berger, O. Diwald, S. Rodrigues and K. J. Klabunde, J. Photochem. Photobiol., A, 2010, 212, 135 .

8I. N. Martyanov, S. Uma, S. Rodrigues and K. J. Klabunde, Chem. Commun., 2004, 2476.

9 S. Sato, Chem. Phys. Lett., 1986, 123, 126.

10 R. Asahi, T. Morikawa, T. Ohwaki, K. Aoki and Y. Taga, Science, 2001, 293(5528), 269.

11 B. Moreno, M. Carballo, J. R. Jurado and E. Chinarro, Bol. Soc. Esp. Ceram. Vidrio, 2009, 48(6), 321.

12 P. C. S. Hayfield, Development of a New Material: Monolithic Ti4 $4 \mathrm{O}_{7}$ Ebonex Ceramic, Royal Society of Chemistry, 2002, ch. 2, p. 9.

13 J. R. Smith and F. C. Walsh, J. Appl. Electrochem., 1998, 28, 1021.

14 E. E. Fardom and D. Pletcher, Electrochim. Acta, 1997, 42(8), 1281.

15 J. R. Smith, J. Appl. Electrochem., 1997, 27, 815.

16 A. Gomes, M. I. da Silva Pereira, M. H. MendoÇa and F. M. Costa, J. Appl. Electrochem., 1995, 25, 1045.

17 V. B. Baez, J. E. Graves and D. Pletcher, J. Electroanal. Chem., 1992, 340, 273.

18 R. R. Miller-Folk, R. E. Noftle and D. Pletcher, J. Electroanal. Chem., 1989, 274, 257.

19 R. J. Pollock, J. F. Houlihan, A. N. Bain and B. S. Coryea, Mat. Res. Bull., 1984, 19, 17.

INSTITUTO

DE INVESTİGAÇÃO

E INOVAÇÃO

EM SAÚDE

UNIVERSIDADE

DO PORTO

Version: Postprint (identical content as published paper) This is a self-archived document from i3S - Instituto de

Rua Alfredo Allen, 208 Investigação e Inovação em Saúde in the University of Porto Open Repository For Open Access to more of our publications, please visit http://repositorio-aberto.up.pt/ 
20 J. R. Smith and F. C. Walsh, J. Appl. Electrochem., 1998, 28, 1021

21 M. Canillas, E. Chinarro, M. Carballo-Vila, J. R. Jurado and B. Moreno, J. Mater. Chem. B, 2013, 1, 6459.

22 M. Carballo-Vila, B. Moreno, E. Chinarro, J. R. Jurado, N. Casañ-Pastor and J. E. Collazos-Castro, Inc. J. Biomed. Mater. Res., 2008, 90A, 94.

23 A. Zachariah, K. V. Baiju, S. Shukla, K. S. Deepa, J. James and K. G. K. Warrier, J. Phys. Chem., 2008, 112, 11345.

24 R. A. Van Leeuwen, C.-J. Hung, D. R. Kammler and J. A. Switzer, J. Phys. Chem., 1995, 99(41), 15247. 


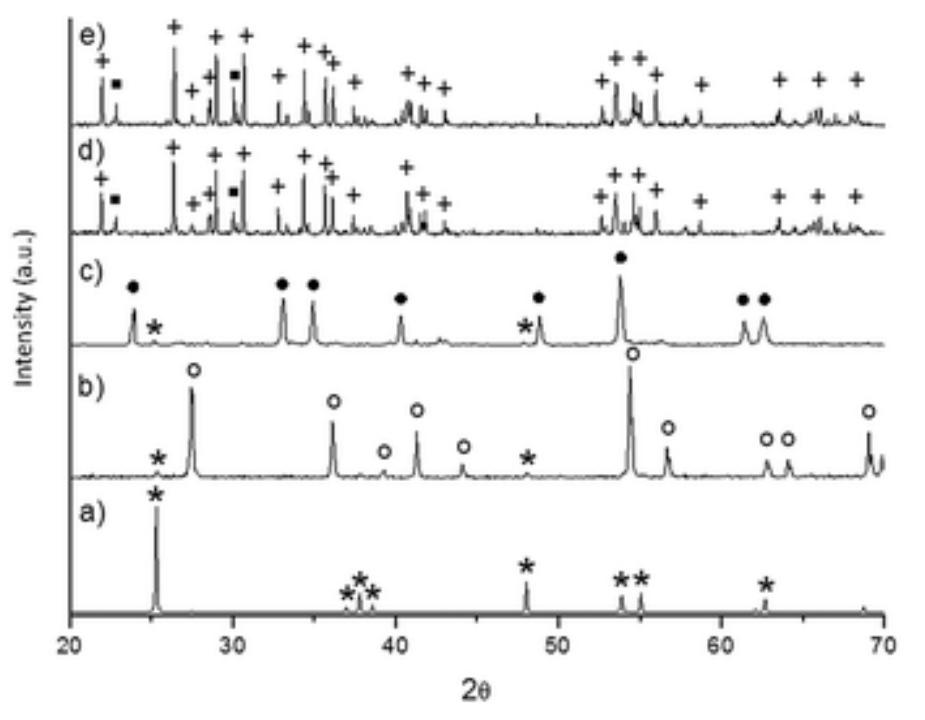

Fig. 1 XRD of powder materials (a) $\mathrm{TiO}_{2}-\mathrm{A},\left(\right.$ b) $\mathrm{TiO}_{2}-\mathrm{R}_{1}$ (c) $\mathrm{Ti}_{2} \mathrm{O}_{31}$ (d) $\mathrm{Ti}_{5} \mathrm{O}_{9}$ and (e) $\mathrm{Ti}_{5} \mathrm{O}_{9}$ after DPPH' assay. Crystal phases are indicated by $(*)$ anatase, $(0)$ rutile, $(\bullet) \mathrm{Ti}_{2} \mathrm{O}_{31}(+) \mathrm{Ti}_{5} \mathrm{O}_{9}$ and $(\mathbf{\bullet}) \mathrm{Ti}_{6} \mathrm{O}_{11}$.

Rua Alfredo Allen, 208 4200-135 Porto 

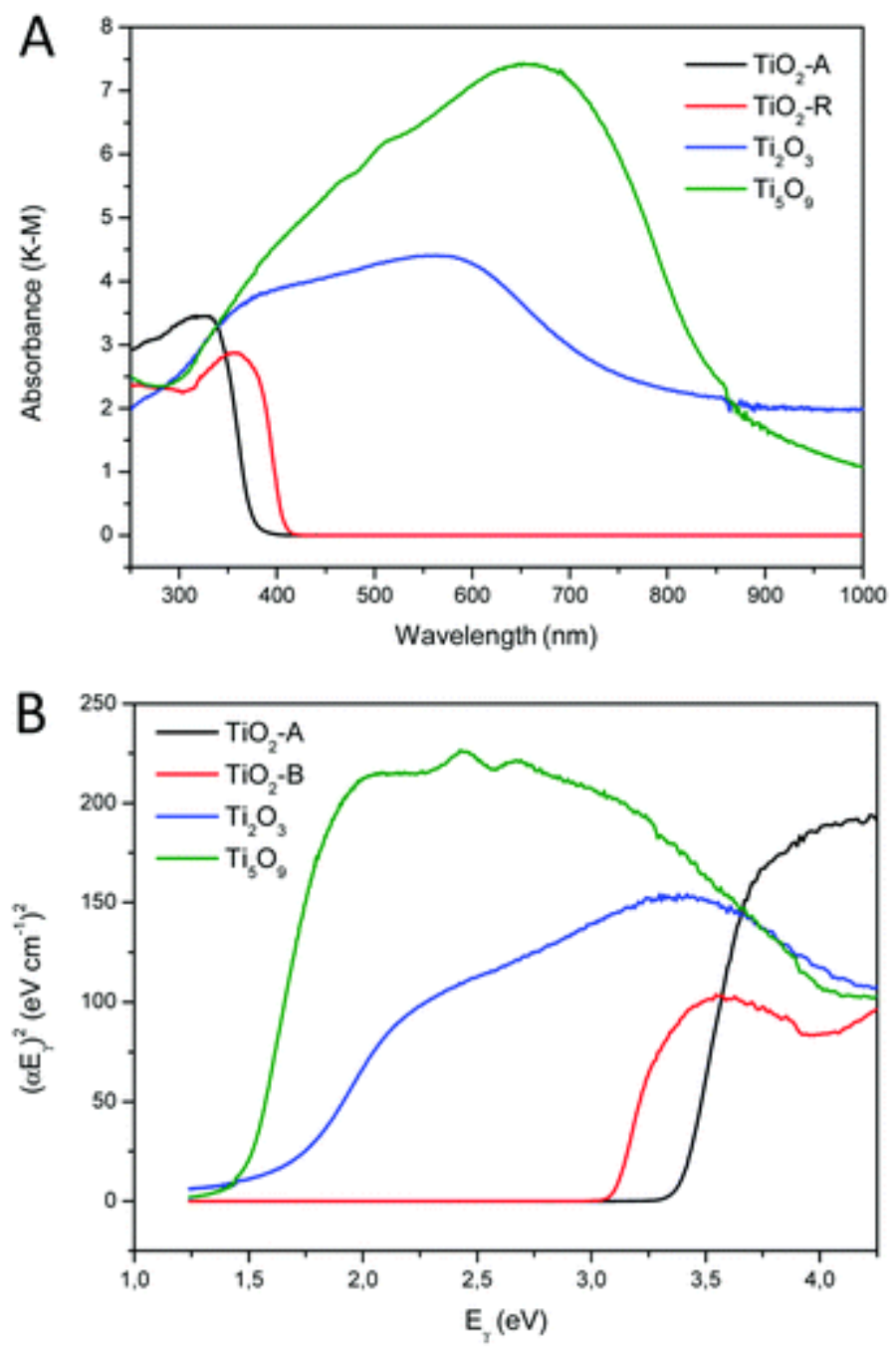

Fig. 2 Band gap calculation of samples from the (A) absorbance spectra using the Kubelka-Munk method and following (B) the transformation in a Tauc plot. The energy-intercept of the fit to the linear regions gives a direct optical band gap. 

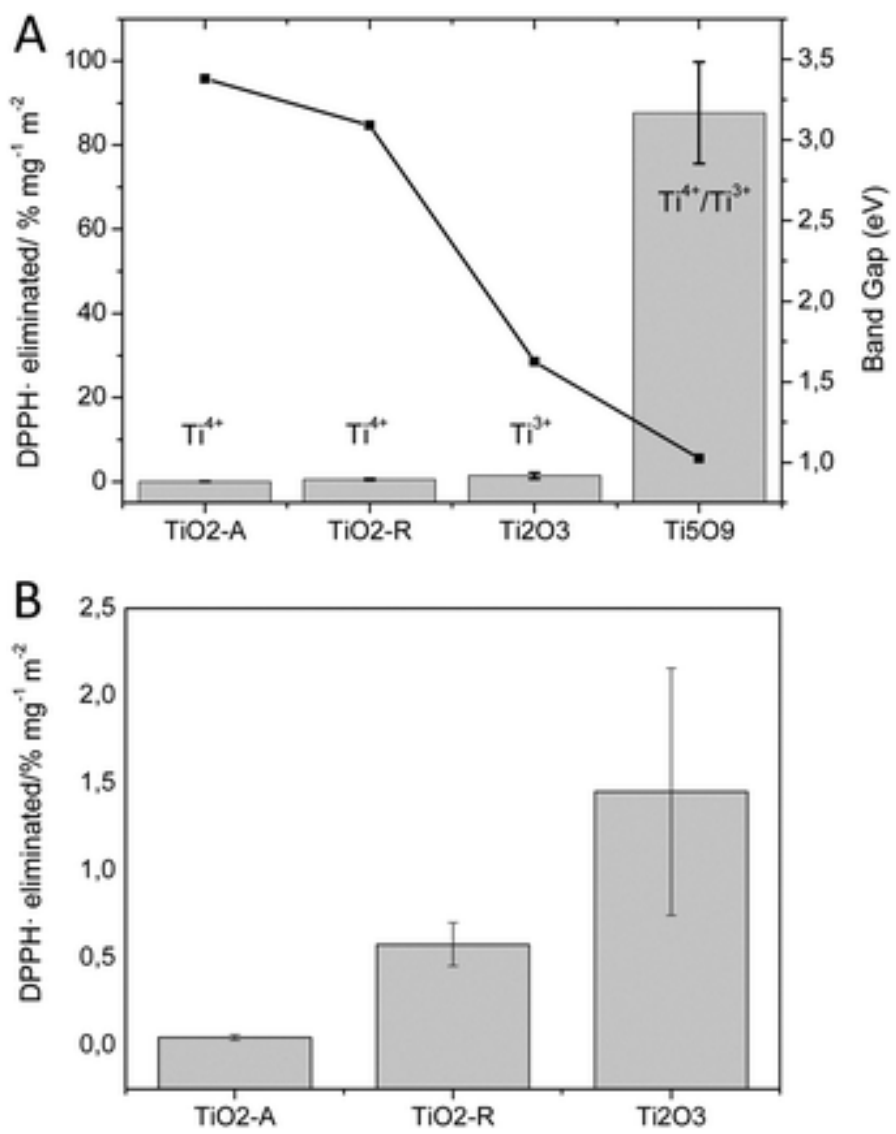

Fig. 3 Percentage of DPPH' eliminated per $\mathrm{mg}$ and $\mathrm{m}^{2}$ after $30 \mathrm{~min}$ (bars) (A) of different $\mathrm{TiO}_{x}$ powders, their band gap (solid line and squares) and their oxidation state. (B) Detailed graph from plot $\mathrm{A}$ of $\mathrm{TiO}_{2}-\mathrm{A}, \mathrm{TiO}_{2}-\mathrm{B}$ and $\mathrm{Ti}_{2} \mathrm{O}_{3} . P$ values are two tailed from a Student's $t$-test. Significant differences are found between all samples assuming $\rho<$ 0.05 

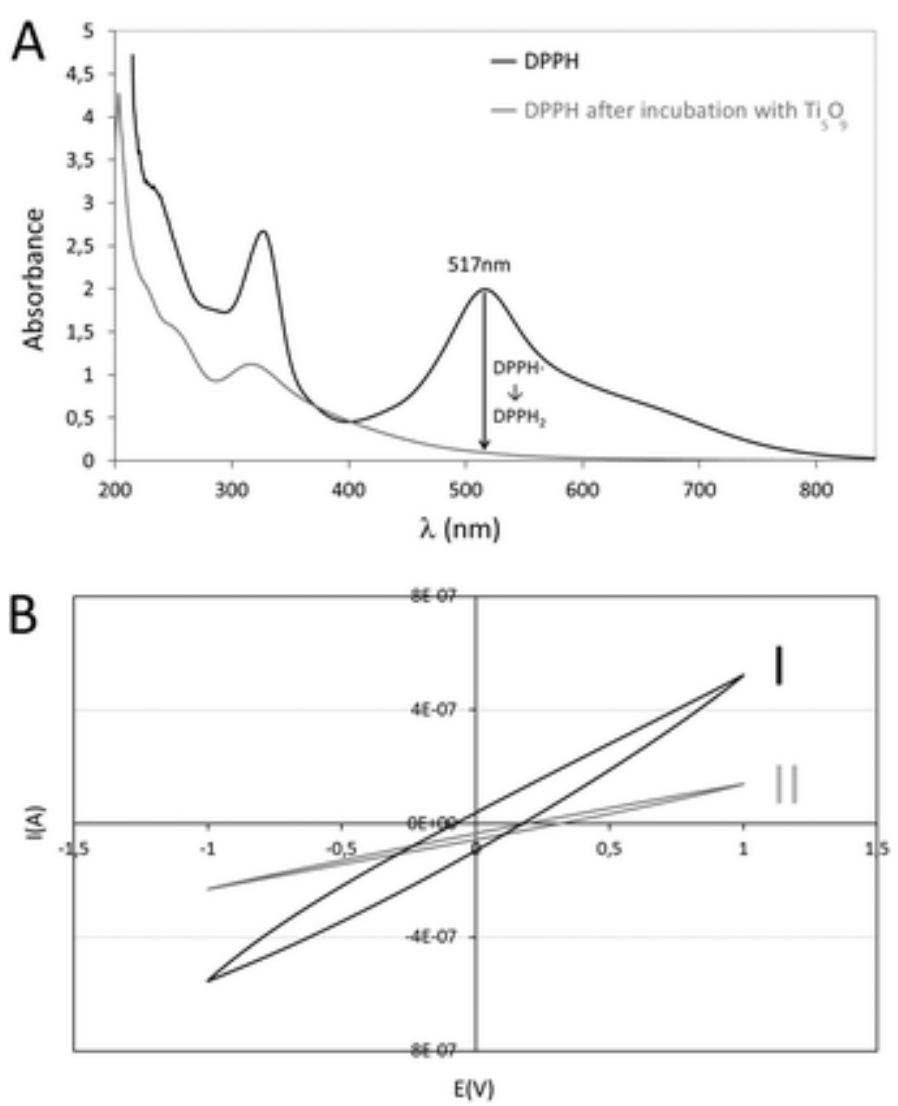

Fig. 4 Assay with $\mathrm{Ti}_{5} \mathrm{O}_{9}$ powders incubated in $3 \mathrm{mM} \mathrm{DPPH}^{\circ}$ solution. (A) After 15 days the absorbance shows the reduction of $\mathrm{DPPH}$ ' to $\mathrm{DPPH}_{2}$. (B) Cyclic voltammetry under dark conditions using $\mathrm{Ti}_{5} \mathrm{O}_{9}$ as the working electrode in $\mathrm{DPPH}^{\circ}$ (I) and isopropanol media (II).

Table 1 Physicochemical characterization of titanium oxide powders

\begin{tabular}{|c|c|c|c|c|c|}
\hline Sample & Anatase (\%) & Rutile (\%) & Specific surface area $\left(\mathrm{m}^{2} \mathrm{~cm}^{-1}\right)$ & Band-gap (eV) & Oxidation states of $\mathrm{Ti}$ \\
\hline $\mathrm{Ti}_{5} \mathrm{O}_{9}$ & - & - & $\leq 0.1$ & 1.02 & $+3 /+4$ \\
\hline $\mathrm{Ti}_{2} \mathrm{O}_{3}$ & - & - & 0.4 & 1.62 & +3 \\
\hline $\mathrm{TiO}_{2}-\mathrm{A}$ & $\geq 99$ & $\leq 1$ & 9.5 & 3.38 & +4 \\
\hline $\mathrm{TiO}_{2}-\mathrm{R}$ & 6 & 94 & 2.0 & 3.09 & +4 \\
\hline
\end{tabular}

